\title{
AVA - A CANVAS NO ENSINO PRESENCIAL: CONTRIBUIÇÕES AS PRÁTICAS DOCENTES
}

FORTALEZA/CE MAIO/2018

\author{
Ana Bruna de Queiroz Pereira - FAS - anabruna3@gmail.com \\ Silviane da Silva Rocha - FAS - silvianerocha@aridesa.com.br \\ Rogério Paulo da Silva - FAS - ropasil@hotmail.com.br \\ Andrey Halyson Lima Barbosa - FAS - bruna.queiroz@aridesa.com.br
}

Tipo: Relato de Experiência Inovadora (EI)

Categoria: Métodos e Tecnologias

Setor Educacional: EDUCAÇÃO SUPERIOR

\begin{abstract}
RESUMO
Este artigo analisou o uso de Ambiente Virtual de Aprendizagem (CANVAS) como apoio a disciplinas no ensino presencial. Esta foi uma pesquisa qualitativa, com base em uma pesquisa de campo de caráter exploratório e descritivo, cujos dados foram elencados a partir de um estudo de caso dos cursos de graduação de uma instituição particular. Foi realizada uma análise como os planos de aprendizagem fazerem uso do AVA e metodologias levantado os desafios que se apresentam quanto ao uso do ambiente virtual como apoio ao ensino presencial. Os resultados apontam que as disciplinas que utilizam o CANVAS no apoio presencial: o alongamento da adesão dos alunos se concretiza; já no planejamento quando o docente sinaliza o uso do Ava, na organização e acesso rápido as atividades $e$ conteúdo e no feedback como ação docente importante para o aprendizado discente.
\end{abstract}

Palavras-chave: Tecnologias na Educação; Canvas; Educação a Distância 


\section{INTRODUÇÃO}

A Sociedade em Rede (CASTELLS,1999) exige pessoas dinâmicas e inovadoras, da mesma forma se faz necessário repensar a forma de agir no mundo, refletir sobre ele e encará-lo, portanto, o docente deve estar aberto as inovações tecnológicas e suas contribuições ao seu fazer docente. Entre as transformações da educação, especificamente no que tange aos aspectos tecnológicos, destacamos a Educação a Distância $(\mathrm{EaD})$ que a partir da popularização do computador e da internet promove crescentes mudanças nas novas formas de ensinar e aprender.

Neste contexto os Ambiente Virtual de Aprendizagem (AVA) se apresentam como elementos importantes e dinamizados do processo de ensinar e aprender online, disponibilizando materiais para leitura complementar, espaços de interação e resolução de dúvidas, chats, jogos, vídeos didáticos, dentre outros recursos que podem ser utilizados conforme as demandas de cada conteúdo, auxiliando o trabalho docente.

O intuito deste trabalho foi evidenciar o potencial dos recursos tecnológicos - utilizados na Educação a Distância e no apoio às atividades do professor no ensino presencial, ou seja, aliar as ferramentas virtuais de aprendizagem ao cotidiano de sala de aula de forma intrisica independentemente da modalidade. Para cumprir esse objetivo, os recursos dos AVA foram aplicados em todas as disciplinas de ensino presencial.

A aliança entre os recursos virtuais facilitados pela internet e o ensino presencial já vem sendo promovida mesmo antes da implementação de cursos totalmente a distância. No entanto, foi com o advento das plataformas AVA, impulsionado pelas necessidades dos cursos $\mathrm{EaD}$, que novas possibilidades educacionais tornaram-se possíveis.

\section{TECNOLOGIAS NA EDUCAÇÃO: APORTE AO FAZER DOCENTE}

O uso de TICs na educação vai para além de se usar ou não, mas o quanto esse uso democratiza,diminuí as desigualdades e qual a amplitude dele para a educação. Kenski afirma que "[...] usamos muitos tipos de tecnologias para aprender e saber mais e precisamos da educação para aprender e saber mais sobre as tecnologias" (2007, p. 45).

Consideramos que a Educação a Distância basicamente consiste em ter alunos e docentes em locais diferentes durante todo ou grande parte do tempo em que aprendem 
e ensinam. Estando em locais distintos estes: "[...] dependem de algum tipo de tecnologia para transmitir informações e Ihes proporcionar um meio para interagir" (MOORE; KEARSLEY, 2008, p.1).

Dessa forma, dada a contemporaneidade e a presença maciça de tecnologias em tudo que diz respeito às atividades humanas, fica quase que impossível conceber a educação sem o uso de tecnologias computacionais. Temos ainda as diversas possibilidades, por meio da internet e da constituição do ciberespaço, das TICs favorecendo a disseminação das informações e a interação entre as pessoas. Lévy afirma que: "[...] o ciberespaço encoraja um estilo de relacionamento quase independente dos lugares geográficos e da coincidência dos tempos" e reforça que:

[...] apenas as particularidades técnicas do ciberespaço permitem que os membros de um grupo humano (que podem ser tantos quantos se quiser) se coordenem, cooperem, alimentem e consultem uma memória comum, e isto quase em tempo real, apesar da distribuição geográfica e da diferença de horários (LÉVY, 1999, p. 49).

A partir do uso crescente de tecnologia e de interação, passa a haver a constituição de comunidades de aprendizagem e surge a quinta geração de Educação a Distância baseada em tecnologias de internet. Uma geração baseada em ensino e aprendizado online, em classes e universidades virtuais. (MOORE e KEARSLEY, 2008).

A sociedade do conhecimento exige pessoas mais dinâmicas e inovadoras, o que só é possível repensando a forma de agir no mundo, pensar sobre ele e encará-lo, portanto o docente deve estar aberto ao que as inovações tecnológicas podem oferecer de contribuição ao seu trabalho cotidiano.

Neste bojo a solução tecnológica do projeto de EaD da Faculdade Ari de Sá envolve a utilização de um Ambiente Virtual de Aprendizagem - AVA, CANVAS, para oferecer aos alunos uma arquitetura da informação adequada aos critérios de navegabilidade e usabilidade.

A construção colaborativa do conhecimento é então viabilizada por alguns recursos de comunicação tais como a ferramenta: fórum temático, ferramenta que visa assegurar a interação, o debate, a problematização e a colaboração. Para a realização de atividades individuais o AVA conta com o questionário, as tarefas online, off-line e de envio de arquivos. Sublinhamos a importância do AVA na capacidade de proporcionar ao aluno interação, acesso a matérias e feedbacks individualizados. 
O questionário é um recurso que permite a criação de atividades com elaboração de questões de diversos tipos: múltipla escolha, abertas, de relacionar, verdadeiro/falso, etc. As atividades consistem na realização de atividades no próprio ambiente, por meio de editor de texto ou fora dele, sendo posteriormente postada em forma de arquivo. É um recurso aberto e flexível, que permite a elaboração de atividades abertas, de resposta a um questionamento, análise de um tema, divulgação de pesquisa realizada, textos reflexivos, estudos de caso e resolução de situações problema.

O AVA possui o recurso Perfil, local onde os participantes podem publicar informações que consideram relevantes sobre si mesmos. Alguns recursos de geração de relatórios são disponibilizados para mapear a participação dos alunos no AVA e seus desempenhos nas atividades, como é o caso dos relatórios de notas, também visualizado pelo aluno, outra forma de registro e acompanhamento é o portfólio do aluno.

Para subsidiar os alunos com orientações importantes à sua plena participação na vida acadêmica, foram criados alguns canais de informação e comunicação, viabilizados pela integração de recursos humanos, material de apoio e recursos do AVA. São eles: Manual do Aluno, Documento de Dúvidas Frequentes, Calendário Acadêmico e Cronograma, Plano de Ensino, Vídeo de apresentação dos módulos, Material Didático Pedagógico das disciplinas, Tutorial de Navegação no AVA e Suporte Técnico.

\section{METODOLOGIA}

Nosso estudo é de natureza qualitativa, partindo da análise de um caso em especifico. Sendo o Lócus de pesquisa na Faculdade Ari de Sá, situada em Fortaleza - CE. Utilizamos como instrumentos de coleta de dados os Planos de Aprendizagem das seguintes disciplinas: Comunicação e Linguagem II, Ciências e Tec. dos Materiais, Direito Civil I, Direito Constitucional I, Psicologia do desenvolvimento e Bases Epistemológicas da Psicologia, Log's do CANVAS e o PPC dos cursos de Psicologia, Direito e Engenharia Civil.

Utilizamos como critérios de seleção das disciplinas as que contemplaram em seu planejamento maior quantidade de ações com utilização de tecnologias e o AVA e com maior adesão por parte dos discentes. Nossos sujeitos de pesquisa foram 9 (nove) docentes ministrantes das disciplinas já indicadas. 
Utilizamos a observação participante junto aos docentes em seu momento de planejamento da disciplina, desta forma buscamos identificar os seguintes aspectos: as atividades propostas aos discentes utilizam tecnologias; como o CANVAS pode auxiliar na disciplina e a importância da tecnologia no processo de ensino - aprendizagem inovador.

\section{ANALISE DOS DADOS}

As análises dos log's do CANVAS apresentam as percentagens de adesão dos discentes às disciplinas deste estudo e bem como que tipos de atividades os discentes realizaram durante as disciplinas em questão. Ao considerarmos a coleta realizada as atividades se caracterizavam como estudos acerca de situações problema, produção de pequenos textos, produção de quadros de análise a partir de textos pré-definidos, vídeos, trechos de filmes. Essas atividades focalizam a aprendizagem ativa e compartilhada que auxiliada pela interconectividade com outras mídias confere dinamismo ao processo educativo.

Os discentes foram levados à análise de situações concretas, à pesquisa individual e grupal, a publicação compartilhada, à construção de portfólio individual e de grupo. No AVA, a comunicação entre alunos, tutores e docentes ocorre de forma síncrona e assíncrona, por meio de mensagens eletrônicas, que seguem com cópia para o e-mail externo. Por meio das atividades desenvolvidas neste espaço é possível articular as diferentes mídias de comunicação (vídeos, websites, chats, entre outros) expandindo a interatividade e viabilizando um processo ensino-aprendizagem centrado no discente e na ação colaborativa e interdisciplinar.

Em nossas análises identificamos que os mais significativos percentuais $74 \%$ e $72 \%$ de adesão discente foram na disciplina de Bases Epistemológicas da Psicologia. Conforme o gráfico abaixo demonstra:

Gráfico 1: Análise de Adesão Discente 


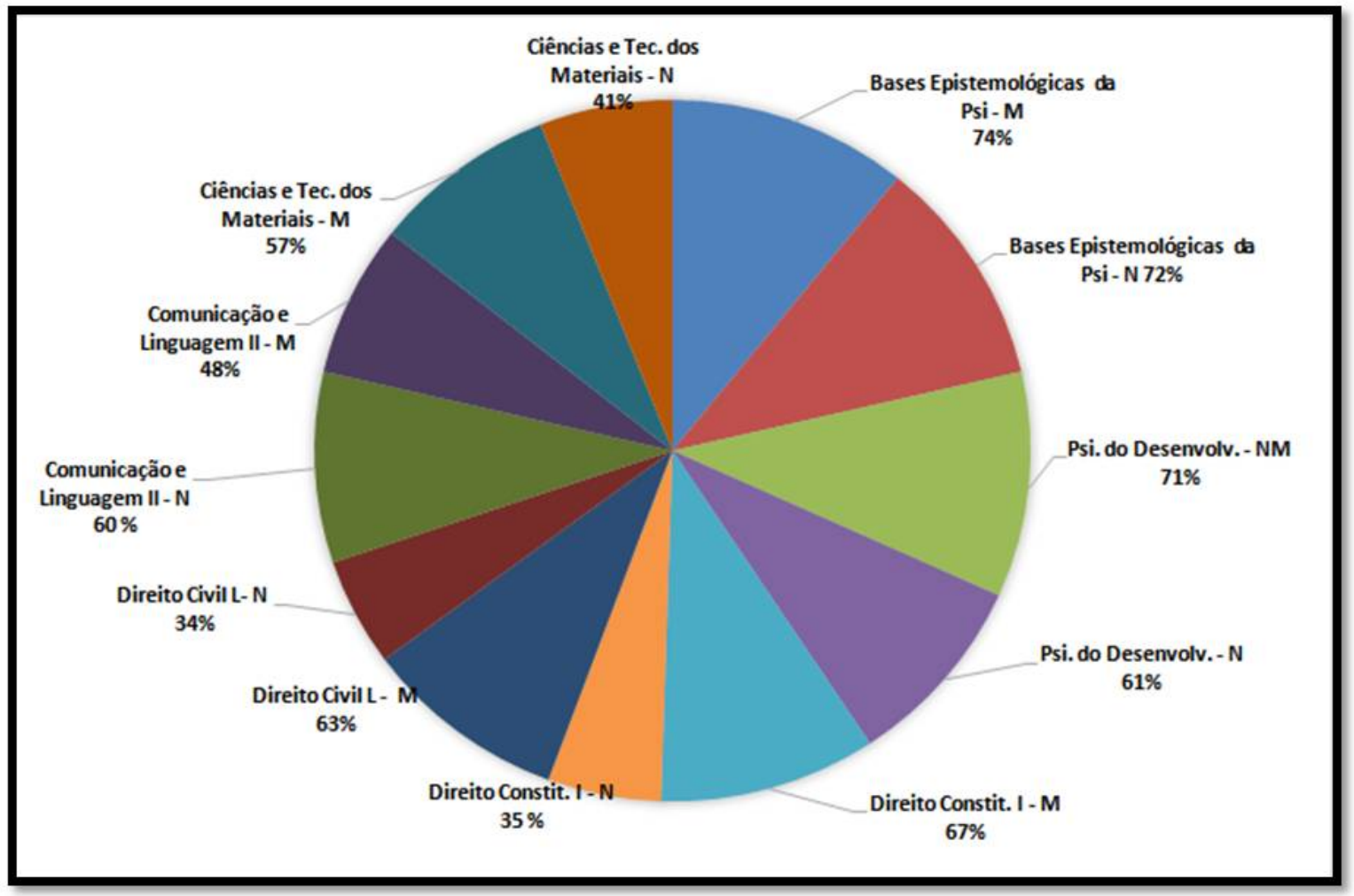

Fonte: Autoria Própria

Consideramos importante destacar que está disciplina se constitui através de atividades constantes em seu plano de aprendizagem que utiliza o CANVAS como apoio em 11 (onze) atividades $100 \%$ subjetivas que versaram sobre as seguintes competências: comparar as bases epistemológicas das teorias; analisar os aspectos de construção das bases epistemológicas da psicologia; avaliar e Interpretar os aspectos históricos que possibilitaram a construção das teorias.

Podemos destacar em comum as disciplinas deste estudo possuem:

- As atividades subjetivas e objetivas são baseadas em resolução de situações problema;

- Docentes conscientes da importância da tecnologia e produção para educação;

- CANVAS potencializa e expande a ação de ensinar e aprender.

O que confere a disciplina a integração com suporte tecnológico e a diversidade de formas de animação e contextualização dos conteúdos estudados. Esta adesão dos alunos caracteriza que o estímulo a utilização destas ferramentas como potencializador da aprendizagem é visto como diferencial qualificador da aprendizagem. As demais disciplinas apresentadas também apresentam em seu escopo utilizado do AVA como ferramentas tecnológicas auxiliares do processo de ensino a aprendizagem também 
índices aceitáveis de adesão e 100\% acima de 50\% de no turno da manhã e acima de $30 \%$ no turno da noite.

\section{CONCLUSÕES}

O uso de tecnologias e suas aplicações na educação são características da Sociedade em Rede (CASTELLS,1999) que se naturaliza no processo de ensinar e aprender em rede de forma flexível e dinamizado.

Desta forma o Ensino Superior vêem construindo formas e usos para a tecnologias proporcionarem novas perspectivas de aprendizado de forma contextualizada e consideramos importante destacar as vantagens do uso do AVA como apoio ao presencial como:

- Aumento de interação entre aluno-aluno, aluno-professor;

- O alongamento do aprendizado dentro e fora da sala de aula;

- A facilidade do acesso aos conteúdos;

- Comunicação rápida e fluida;

- Envio de trabalhos de forma rápida, fácil e ágil;

- Correção dos trabalhos com feedbacks assertivos e direcionados;

- Controle na entrega de trabalho;

- Aplicação de conteúdos complementares.

As diversas possibilidades que a inserção dos traz ao ensino uma realidade inegável às Instituições de Ensino Superior. Esta ferramenta de apoio aliada ao ensino presencial cria novos instrumentos de estímulo, possibilitando a construção de conhecimento, significativo de cunho formativo, conceitual e de mercado. Essa é uma necessidade emergente que se alinha ao perfil cada vez mais interativo dos adolescentes e jovens atuais, capaz de fornecer instrumentos modernos e atraentes aos alunos do novo milênio, "o conectado". O fato de haver um local onde os alunos podem interagir entre si e com o professor, tirando dúvidas e favorecendo a própria construção do conhecimento, é algo que poderá transformar de forma significativa a educação. 


\section{REFERÊNCIAS}

ANDRADE, Maria Margarida de. Introdução à metodologia do trabalho científico: elaboração de trabalhos na graduação. 5. ed. São Paulo: Atlas, 2001.

BRASIL. Ministério da Educação (MEC). Educação Superior a Distância. Portaria № 4.059, de 10 de Dezembro de 2004 (DOU de 13/12/2004, Seção 1, p. 34). Disponível em: http://portal.mec.gov.br/sesu/acs_portaria4059.pdf. Acesso em mai. 2018.

INSTITUTO FEDERAL DO ESPÍRITO SANTO (IFES). Resolução CS no 64, de 08 de Dez. de 2011. Instituto Federal do Espírito Santo. Vitória: ES, 2011. Disponível em: http://www.ifes.edu.br/images/stories/files/Institucional/conselho_superior/2011/RES_CS 64_2011_Normatiza\%20Utiliza\%C3\%A7\%C3\%A30\%20Tecnologias\%20Informa\%C3\% A7\%C3\%A30\%E2\%80\%A6.pdf. Acesso em mai. 2018 .

KENSKI, Vani Moreira. Educação e Tecnologias: o novo ritmo da informação. Campinas, SP: Papirus, 2007.

LÉVY, P. Cibercultura. São Paulo: Editora 34, 1999.

MARCONI, Marina de Andrade; LAKATOS, Eva Maria. Fundamentos deMetodologia Científica. 5aㅗ ed. São Paulo: Atlas, 2003.

MOORE, Michael G., KEARSLEY, Greg. Educação a distância: uma visão integrada. São Paulo: Cengage Learning, 2008.

PRENSKY, Marc. A aprendizagem baseada em jogos digitais. São Paulo: Editora do SENAC São Paulo, 2012. 546 p.

STAKE, Robert E. Pesquisa qualitativa: estudando como as coisas funcionam. (Trad.) Karla Reis. Porto Alegre: Penso, 2011.

VYGOTSKY,Lev Semenovich. A formação social da mente.6.ed.SãoPaulo:Martins Fontes, 1998. 